Full Length Article

\title{
Vitamin D deficiency is associated with poor breast cancer prognostic features in postmenopausal women
}

\author{
Benedito de Sousa Almeida-Filho, Heloisa De Luca Vespoli, Eduardo Carvalho Pessoa, \\ Murilo Machado, Jorge Nahas-Neto, Eliana Aguiar Petri Nahas* \\ Department of Gynecology and Obstetrics, Botucatu Medical School, Sao Paulo State University—UNESP, Sao Paulo, Brazil
}

\section{A R T I C L E I N F O}

\section{Keywords:}

Postmenopausal women

Vitamin D

Breast cancer

Immunohistochemical profile

\begin{abstract}
A B S T R A C T
This study aimed to evaluate the association between pretreatment vitamin D (VD) deficiency with breast cancer prognostic features in Brazilian postmenopausal women. An analytical cross sectional study was conducted with 192 women, aged 45-75 years, attended at University Hospital. Women with recent diagnosis of breast cancer, in amenorrhea $>12$ months and age $\geq 45$ years, without medication use or clinical conditions that interfere with VD values were included. Clinical and anthropometric data were collected. Serum level of 25 hydroxyvitamin D [25(OH)D] was measured in all patients until 20 days after breast cancer diagnosis, and was classified as normal ( $\geq 30 \mathrm{ng} / \mathrm{mL}$ ), insufficiency $(20-29 \mathrm{ng} / \mathrm{mL})$ and deficiency $(<20 \mathrm{ng} / \mathrm{mL})$. Data on breast cancer (histopathological type, grade, tumor stage, lymph node status), hormone status (estrogen receptor, ER, progesterone receptor, PR), human epidermal growth factor receptor type 2 (HER2) and epithelial proliferative activity (Ki-67) were collected. For statistical analysis, the t-student test, the Gamma Distribution (asymmetric variables), the chi-square test and the logistic regression (OR-odds ratio) were used. The median 25(OH)D level was $25.8 \mathrm{ng} / \mathrm{mL}$ (range 12.0-59.2 ng/mL). Sufficient vitamin D levels were detected in 65 patients $(33.9 \%$ ), whereas insufficient levels in 92 patients (47.9\%), and deficient levels in 35 patients (18.2\%). Participants with insufficient and deficient 25(OH)D levels had a higher proportion of tumors with a high grade and locally advanced and metastatic disease, more positive lymph node, a lower proportion of ER, PR positives tumors and higher Ki-67( $\mathrm{p}<0.05)$. Patients with normal vitamin D had a higher frequency of luminal A (47.7\%) and luminal B (32.2\%) tumors when compared to patients with vitamin D insufficiency or deficiency. Furthermore, all cases of triple negative were detected in women with low VD levels. Multivariate analysis, after adjusting for age, time since menopause and BMI, showed that insufficient and deficient level of vitamin D were significantly associated with negative estrogen receptor (OR 3.77 CI 95\% 1.76-8.09 and OR 3.99 CI 95\% 1.83-8.68), high Ki67 (OR 2.50, CI 95\% 1.35-4.63, and OR 2.62, CI 95\% 1.40-4.98), and positive axillary lymph node status (OR 1.59, CI 95\% 1.03-2.33, and OR 1.58, CI 95\% 1.02-2.92) respectively. In Brazilian postmenopausal women with breast cancer, there was an association between vitamin D insufficiency or deficiency and tumors with worse prognostic features. Low vitamin D levels were shown to be a risk factor for ER negative tumors, with positive axilla and a higher rate of cell proliferation.
\end{abstract}

\section{Introduction}

Breast cancer is the type of cancer that mostly affects women in the world, both in developing and developed countries. It is also the leading cause of death by cancer in women worldwide, with an estimated 520,000 deaths annually [1]. In Brazil, the National Cancer Institute (INCA) estimates 57,960 new cases of breast cancer to be diagnosed in
2017, accounting for an estimated risk of 56.20 cases per 100,000 women [2]. The prognosis of breast cancer patients is directly related to the disease stage at the time of diagnosis and may be inferred by factors and biomarkers that can provide information on the biological potential and most likely clinical course irrespective of treatment [3]. For that reason, breast cancer is currently acknowledged as a heterogeneous disease, comprising a wide spectrum of morphologically different

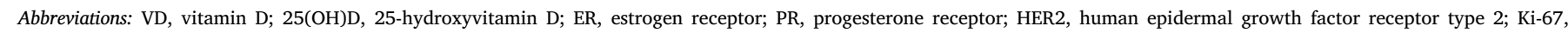

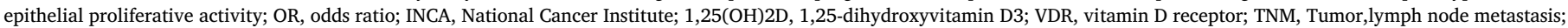
BMI, body mass index; IHC, Immunohistochemistry

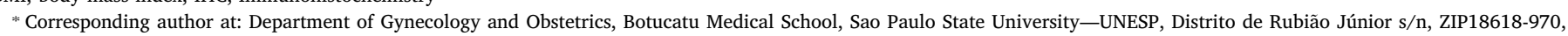
Botucatu, SP, Brazil.

E-mail addresses: epetri@fmb.unesp.br, elianapetrinahas@gmail.com (E.A.P. Nahas).
} 
subtypes and resulting in distinct biological behaviors, presentations and prognoses [4].

Standard clinicopathological factors such as patient age, menopausal status, tumor size, tumor histology and grade,lymph node status and tumor stage continue to be useful in estimating prognosis [4]. Assessment of biological and molecular patterns has also been considered an important tool not only for prognosis, but also for deciding which treatment modality is best for each individual patient [5]. Estrogen receptor (ER), progesterone receptor (PR), human epidermal growth factor receptor type 2 (HER2) and Ki-67, an index of tumor proliferative rate, are currently detected by immunohistochemistry (IHC) technique and used to estimate prognosis and to categorize breast cancer into intrinsic molecular subtypes that exhibit similar morphological and prognostic features (luminal A, luminal B, HER2-overexpressing, and triple negative cancers) [4].

In addition, a number of other breast cancer-related etiological and prognostic factors have been identified as its molecular pathogenesis is still not clear. It has been recently reported that vitamin $\mathrm{D}$ and its receptor could play an important role in breast cancer pathogenesis $[6,7]$. Vitamin D acts by binding to the vitamin D receptor (VDR), which is expressed in the breast tissue. The VDR controls the expression of genes that regulate cell proliferation, differentiation, and apoptosis $[8,9]$. Evidence from several trials supports that low levels of 25 hydroxyvitamin D [25(OH)D] are associated with an increased risk of breast cancer [10-14]. However, some prospective studies have not shown any association [15-19]. Circulating 25(OH)D is considered the best marker of vitamin D status because it reflects the vitamin D obtained from both diet/supplements and sun exposure and has a longer half-life when compared to 1,25-dihydroxyvitamin D3 [1,25(OH)2D] [20].

Researchers have demonstrated that vitamin $\mathrm{D}$, as activated 1,25$(\mathrm{OH}) 2 \mathrm{D}$, influences events at the cellular level that are potentially important not only for the pathogenesis of breast cancer, but also for its prognosis and survival [21-23]. In fact, studies have been focusing in addressing this possible relation of vitamin $\mathrm{D}$ levels and breast cancer with worse prognosis [23]. An understanding of the prognostic significance of vitamin D in patients with breast cancer may identify a high-risk patient subgroup. Therefore, in our study, we aimed at analyzing the association between pretreatment vitamin D deficiency and the prognostic features of breast cancer and at evaluating the relationship between vitamin D deficiency and the current molecular subtypes of breast cancer in Brazilian postmenopausal women.

\section{Methods}

\subsection{Study design and sample selection}

This is a cross sectional study. The population group comprised 192 Brazilian postmenopausal women recently diagnosed with breast cancer, aged 45 to 75 years, who attended the Breast Disease Assessment Center of the University Hospital in Southeastern Brazil during 2015-2016. Women with the following features were included: histological diagnosis of breast cancer, last menstruation dating at least 12 months prior to presentation, and aging 45 years or older. Exclusion criteria were: pharmacological use of any doses of VD; in situ breast carcinoma; personal history of other cancers; renal failure (creatinine $>1.4 \mathrm{mg} / \mathrm{dL}$ ); liver diseases; abusive alcohol consumption and grade III obesity. This study was performed in compliance with the Helsinki Declaration. Informed consent was obtained from all participants and the study was approved by the Research Ethics Committee of the Botucatu Medical School, Sao Paulo State University (UNESP).

All participants underwent individual interviews in which the following data were collected: age, menopausal age, time since menopause, parity, age of first gestation, duration of breastfeeding, current smoking, prior use of hormone therapy, history of chronic diseases, family history of breast cancer and use of medications. Smokers were defined as patients who reported smoking, regardless of the number of cigarettes smoked. Anthropometric data included weight, height, and body mass index (BMI; weight/height ${ }^{2}$ ). BMI were classified according to the system used by the World Health Organization in 2002: less than $24.9 \mathrm{~kg} / \mathrm{m} 2$ as normal, from 25 to $29.9 \mathrm{~kg} / \mathrm{m} 2$ asoverweight, from 30 to $34.9 \mathrm{~kg} / \mathrm{m} 2$ as grade I obesity, from 35 to $39.9 \mathrm{~kg} / \mathrm{m} 2$ as grade II obesity, and $40 \mathrm{~kg} / \mathrm{m} 2$ or greater as grade III obesity [24].

\subsection{Vitamin D assessment}

Serum VD assessment was collected immediately after diagnosis of breast cancer and prior to any proposed treatment, up to 20 days postdiagnosis. For serum 25(OH)D dosage, the 25-OH Vitamin D assay kit by the Architect ${ }^{\circ}$ i2000 analyzer (Abbott ${ }^{\circ}$, Santa Clara, California, USA) was used, which performs chemiluminescent microparticle immunoassay (CMIA). The detection limit was $1.9 \mathrm{ng} / \mathrm{mL}$ and the intraand inter-assay coefficient of variation was $<10 \%$, as described in the assay kit. Serum 25(OH)D levels were classified as normal ( $\geq 30 \mathrm{ng}$ / $\mathrm{mL})$, insufficiency $(20-29 \mathrm{ng} / \mathrm{mL})$ and deficiency $(<20 \mathrm{ng} / \mathrm{mL})[20]$. All laboratory tests were processed by the Clinical Analysis Laboratory of the Botucatu Medical School.

\subsection{Tumor features}

Breast cancer tumors were classified according to established prognostic features: tumor size, type and histological staging, grade, axillary lymph node status, hormone receptor status and epithelial proliferative activity. The tumor diameter was obtained from histopathological reports and histologically graded as grade 1 (well differentiated), grade 2 (moderately differentiated), and grade 3 (undifferentiated) according to the method proposed by Elston and Ellis, which uses architectural aspects, nuclear differentiation levels, and mitotic index as criteria [25]. The axillary lymph node status was classified as positive if at least one lymph node were identified as having breast cancer metastasis based on histopathological examination. Tumors were classified according to 7th edition of the American Joint Committee on Cancer (AJCC) TNM (Tumor,lymph Node, Metastasis) system [26], grouped into stages (I-IV) and categorized according to the National Comprehensive Cancer Network (NCCN) classification, which further divides breast cancer staging into three categories based on management options: 1- localized invasive breast cancer (stage I, II and T3 N1 M0, the latter considered to be an operable locally advanced breast cancer), 2- inoperable locally advanced invasive breast cancer (stage III, except T3 N1 M0), and 3- metastatic disease (stage IV) [26].

The hormone receptor status and epithelial proliferative activity were assessed by standard methods, using immunohistochemistry for estrogen receptor (ER), progesterone receptor (PR), human epidermal growth factor receptor 2 (HER2) and cell proliferation index (Ki-67) status. Breast cancer was then categorized into four molecular subtypes based on surrogate immunohistochemical profiles: luminal A (ER + and/or PR +, HER2-, Ki-67 < 14\%); luminal B (ER + and/or PR +, HER2-/ + , Ki-67 $\geq 14 \%$ ), non-luminal HER2 (ER-, PR- and HER2 + ), and triple negative (ER-, PR- and HER2-) [4]. Immunohistochemistry (IHC) with antibodies for ER, PR, HER2, Ki-67 was performed according to the streptavidin-biotin-peroxidase complex methods (DakoCytomation $^{\circledR}$, Glostrup, Denmark). ER and PR were considered positive if $>1 \%$ of cells stained positive on IHC [27]. Ki-67 was considered high if $\geq 14 \%$ of the tumor cells were labeled [5]. HER2 was considered positive if IHC was $3+$, or if the fluorescence in situ hybridization (FISH), systematically performed in all IHC $2+$ tumors, showed HER2 genomic amplification [28]. All histopathological and immunohistochemical analyses were performed by the Department of Pathology of Botucatu Medical School. Histologic grade, ER status and molecular subtypes defined by ER, PR, HER2 and Ki-67 were used as independent prognostic features of breast cancer. 


\subsection{Statistical analysis}

The sample size estimation was based on the study by Kermani et al. [29] who found a difference in the HER2 + between women with and without vitamin deficiency (12 and 2 cases, respectively). Considering the difference between the values and correcting the estimate for type I (5\%) and type II (20\%) errors attributed to the study, the estimated sample size was at least 153 women with breast cancer. From the data, tables were constructed based on VD serum values (normal $\geq 30 \mathrm{ng} / \mathrm{mL}$, insufficiency $20-29 \mathrm{ng} / \mathrm{mL}$, and deficiency $<20 \mathrm{ng} / \mathrm{mL}$ ). For data analysis, means ( \pm standard deviations) were calculated for quantitative variables, and percentages were calculated for qualitative variables. For comparison between the groups in relation to quantitative features, Student's $t$-test and gamma distribution (asymmetric) were used. Chi-Square test was used to assess the association between the frequencies of categorical features. Multivariate analysis was performed by binary logistic regression, considering a $95 \%$ confidence interval $(\mathrm{CI})$, with a respective odds ratio (OR), to examine the association between serum vitamin $\mathrm{D}$ (dependent variable or response) and the breast cancer prognostic features (independent or explanatory variables), adjusted for age, time since menopause and BMI (confounding variables). A level of significance of $5 \%$ or the corresponding $P$ value was adopted in all tests. The analyses were performed using the Statistical Analysis System (SAS) 9.2 Software.

\section{Results}

\subsection{Sample description}

One hundred and ninety two postmenopausal women with a mean age at diagnosis of $61.3 \pm 9.6$ years old were enrolled in the study. Serum samples were drawn up to 20 after diagnosis, and the mean 25(OH)D level was $25.8 \mathrm{ng} / \mathrm{mL}$ (ranging from 12.0 to $59.2 \mathrm{ng} / \mathrm{mL}$ ). Patients were classified based on serum $25(\mathrm{OH}) \mathrm{D}$ concentrations into three groups: normal or sufficient $(\geq 30 \mathrm{ng} / \mathrm{mL})$, insufficiency $(20-29 \mathrm{ng} / \mathrm{mL})$, and deficiency $(<20 \mathrm{ng} / \mathrm{mL})$. Sufficient vitamin D levels were detected in 65 patients (33.9\%), whereas insufficient levels in 92 patients (47.9\%), and deficient levels in 35 patients (18.2\%). Clinical features according to serum 25-hydroxy vitamin D level are shown in Table 1. No differences in age, time of menopause, parity, BMI, smoking, hormone replacement therapy use and history of hypertension or diabetes were observed.

\subsection{Associations of vitamin D levels with tumor features}

The associations of vitamin D levels with tumor features are shown in Table 2. When comparing vitamin $\mathrm{D}$ and clinicopathological
Table 2

Comparison of clinicopathological variables based on serum of 25-hydroxyvitamin D level, normal ( $\geq 30 \mathrm{ng} / \mathrm{mL}$ ), insufficiency $(20-30 \mathrm{ng} / \mathrm{mL})$ and deficiency $(<20 \mathrm{ng} / \mathrm{mL})$.

\begin{tabular}{|c|c|c|c|c|}
\hline Variables & $\begin{array}{l}\text { Normal } \\
(\mathrm{n}=65)\end{array}$ & $\begin{array}{l}\text { Insufficiency } \\
(\mathrm{n}=92)\end{array}$ & $\begin{array}{l}\text { Deficiency } \\
(\mathrm{n}=35)\end{array}$ & $P$ value \\
\hline $\begin{array}{l}\text { Tumor size }(\mathrm{cm}), \mathrm{n} \\
\quad(\%)\end{array}$ & & & & 0.693 \\
\hline$\leq 2$ & $19(29.2)$ & $25(27.2)$ & $13(37.1)$ & \\
\hline $2-5$ & $40(61.6)$ & $57(62.0)$ & $17(48.6)$ & \\
\hline$\geq 5$ & $6(9.2)$ & $10(10.9)$ & $5(14.3)$ & \\
\hline $\begin{array}{l}\text { Histology of BC, } \mathrm{n} \\
(\%)\end{array}$ & & & & 0.382 \\
\hline Ductal & $62(95.4)$ & $88(95.7)$ & $34(97.1)$ & \\
\hline Lobular & $3(4.6)$ & $4(4.3)$ & $1(2.9)$ & \\
\hline Grade, n (\%) & & & & 0.017 \\
\hline Low & $9(13.8)$ & $6(6.5)$ & $1(2.8)$ & \\
\hline Intermediate & $38(58.5)$ & $47(51.1)$ & $13(37.1)$ & \\
\hline High & 18 (27.7) & $39(42.4)$ & $21(60.1)$ & \\
\hline $\begin{array}{l}\text { Tumor NCCN } \\
\text { staging, n (\%) }\end{array}$ & & & & 0.047 \\
\hline Localized disease & $50(76.9)$ & $58(63.0)$ & $20(57.1)$ & \\
\hline $\begin{array}{l}\text { Inoperable locally } \\
\text { advanced } \\
\text { disease }\end{array}$ & $12(18.5)$ & $20(21.7)$ & $10(28.6)$ & \\
\hline Metastatic disease & $3(4.6)$ & $14(15.3)$ & $5(14.3)$ & \\
\hline LN status, n (\%) & & & & 0.0042 \\
\hline negative & $39(60.0)$ & 31 (33.7) & $14(40.0)$ & \\
\hline positive & $26(40.0)$ & $61(66.3)$ & $21(60.0)$ & \\
\hline $\begin{array}{l}\text { Estrogen Receptor, } \\
\text { n (\%) }\end{array}$ & & & & 0.0001 \\
\hline Positive & $61(93.8)$ & $77(83.4)$ & $21(60.0)$ & \\
\hline Negative & $4(6.2)$ & 15 (16.6) & $14(40.0)$ & \\
\hline $\begin{array}{l}\text { Progesterone } \\
\quad \text { Receptor, n (\%) }\end{array}$ & & & & 0.047 \\
\hline Positive & $52(80.0)$ & $63(68.5)$ & $20(57.1)$ & \\
\hline Negative & $13(20.0)$ & $29(31.5)$ & $15(42.9)$ & \\
\hline HER2, n (\%) & & & & 0.905 \\
\hline Positive & $13(20.0)$ & $19(20.6)$ & $6(17.1)$ & \\
\hline Negative & $52(80.0)$ & $73(79.4)$ & $29(82.9)$ & \\
\hline Ki-67, n (\%) & & & & 0.0006 \\
\hline$<14 \%$ & $32(49.2)$ & $25(27.2)$ & $5(14.3)$ & \\
\hline$\geq 14 \%$ & $33(50.8)$ & $67(72.8)$ & $30(85.7)$ & \\
\hline $\begin{array}{l}\text { Intrinsic subtype, } \mathrm{n} \\
\text { (\%) }\end{array}$ & & & & $<0.0001$ \\
\hline Luminal A & 31 (47.7) & $22(23.9)$ & $2(5.7)$ & \\
\hline Luminal B & $21(32.3)$ & 45 (48.9) & $14(40.0)$ & \\
\hline $\begin{array}{l}\text { non-luminal } \\
\text { HER2 }\end{array}$ & $13(20.0)$ & $19(20.6)$ & $6(17.1)$ & \\
\hline Triple negative & $0(0.0)$ & $6(6.6)$ & $13(37.2)$ & \\
\hline
\end{tabular}

BC, breast cancer; NCCN, National Comprehensive Cancer Network; LN, lymph node;HER2, human epidermal growth factor receptor type 2.

Table 1

Comparison of clinical features based on serum of 25 -hydroxyvitamin D level, normal ( $\geq 30 \mathrm{ng} / \mathrm{mL}$ ), insufficiency (20-30 ng/mL) and deficiency ( $<20 \mathrm{ng} / \mathrm{mL})$.

\begin{tabular}{|c|c|c|c|c|}
\hline Variables & Normal $(n=65)$ & Insufficiency $(\mathrm{n}=92)$ & Deficiency $(n=35)$ & P value \\
\hline Age (years), mean $\pm \mathrm{SD}$ & $60.7 \pm 9.6 a$ & $61.2 \pm 9.2 \mathrm{a}$ & $61.9 \pm 10.3 a$ & 0.711 \\
\hline Age of menarche (years), mean \pm SD & $13.1 \pm 1.6 \mathrm{a}$ & $12.8 \pm 1.6 \mathrm{a}$ & $12.8 \pm 1.2 \mathrm{a}$ & 0.530 \\
\hline Age at menopause (years), mean \pm SD & $48.4 \pm 3.8 \mathrm{a}$ & $48.8 \pm 3.5 \mathrm{a}$ & $48.1 \pm 3.1 \mathrm{a}$ & 0.614 \\
\hline Time of menopause (years), mean $\pm S D$ & $12.3 \pm 10.3 a$ & $12.5 \pm 9.1 \mathrm{a}$ & $13.3 \pm 10.5 a$ & $0.659^{\S}$ \\
\hline Parity (no. of children), mean \pm SD & $2.9 \pm 2.2 \mathrm{a}$ & $2.7 \pm 1.9 a$ & $2.8 \pm 1.9 \mathrm{a}$ & $0.850^{\S}$ \\
\hline First pregnancy age (years), mean \pm SD & $22.3 \pm 4.9 \mathrm{a}$ & $22.8 \pm 5.6 \mathrm{a}$ & $22.2 \pm 4.1 \mathrm{a}$ & 0.713 \\
\hline Breast-feeding (months), mean $\pm \mathrm{SD}$ & $29.1 \pm 34.4 \mathrm{a}$ & $28.4 \pm 36.4 a$ & $30.7 \pm 39.4 a$ & $0.343^{\S}$ \\
\hline BMI $\left(\mathrm{kg} / \mathrm{m}^{2}\right)$, mean \pm SD & $31.0 \pm 5.1 \mathrm{a}$ & $31.0 \pm 5.5 \mathrm{a}$ & $30.0 \pm 3.9 \mathrm{a}$ & 0.578 \\
\hline $25(\mathrm{OH}) \mathrm{D}(\mathrm{ng} / \mathrm{mL})$, mean $\pm \mathrm{SD}$ & $35.0 \pm 6.0 \mathrm{a}$ & $24.8 \pm 2.8 b$ & $17.1 \pm 2.5 c$ & $<0.0001$ \\
\hline Family history of BC, n (\%) & $10(15.4)$ & $18(19.6)$ & $7(20.0)$ & $0.634^{\#}$ \\
\hline Smoking, n (\%) & $11(16.9)$ & $14(15.2)$ & $6(17.1)$ & $0.809^{\#}$ \\
\hline HT use, n (\%) & $10(15.4)$ & $8(8.7)$ & $4(11.4)$ & $0.305^{\#}$ \\
\hline Hypertension, $\mathrm{n}(\%)$ & $30(46.2)$ & $52(56.5)$ & $18(51.4)$ & $0.438^{\#}$ \\
\hline Diabetes, n (\%) & 9 (13.9) & $20(21.7)$ & $8(22.8)$ & $0.295^{\#}$ \\
\hline
\end{tabular}

25(OH)D, 25-hydroxy vitamin D; BMI, body mass index; BC, breast cancer; HT, hormone therapy.

p-value $(a, b)$ show significant differences between groups and $(a, a)$ without difference $(p>0.05)$ (ANOVA, Gamma distribution ${ }^{\S}$ or Chi-square Test $^{\#}$ ). 
parameters, we observed that low vitamin D level was significantly detected mainly in cases with poor prognosis. Participants with insufficient and deficient 25(OH)D levels had a higher proportion of tumors with high grade, locally advanced and metastatic disease, more positive lymph nodes, a lower proportion of ER, PR-positive tumors and higher Ki-67 indices. There was a significant association between vitamin D concentration and intrinsic subtypes. Patients with normal vitamin D had a higher frequency of luminal A (47.7\%) and luminal B (32.2\%) tumors when compared to patients with vitamin $\mathrm{D}$ insufficiency or deficiency. Furthermore, all cases of triple negative were detected in women with low vitamin D levels. There were no significant associations between vitamin D concentration and tumor size, histology of breast cancer and HER2 status (Table 2).

\subsection{Multivariate analysis of variables according to deficient of 25(OH) D} levels

Multivariate analysis, after adjusting for age, time since menopause and BMI, showed that insufficient and deficient level of vitamin D were associated with negative estrogen receptor (OR 3.77 CI 95\% 1.76-8.09, $\mathrm{p}=0.0007$ and OR $3.99 \mathrm{CI} 95 \% 1.83-8.68, \mathrm{p}=0.0005$, respectively), high Ki-67 (OR 2.50, CI 95\% 1.35-4.63, p $=0.003$ and OR 2.62, CI $95 \% 1.40-4.98, \mathrm{p}=0.003$, respectively), and positive axillary lymph node status (OR 1.59, CI 95\% 1.03-2.33, $\mathrm{p}=0.048$ and OR 1.58, CI $95 \% 1.02-2.92, \mathrm{p}=0.042$, respectively) (Table 3 ). Other clinicopathological variables did not show significance.

\section{Discussion}

In this study, we evaluated the long-standing interest in studying the relationship and potential impact of vitamin D level in patients with newly diagnosed breast cancer. We specifically studied postmenopausal women as they comprise an important risk group for breast cancer and hypovitaminosis D. Partly because numerous trials have been investigating the association between circulating vitamin $\mathrm{D}$ levels and breast cancer risk, but few have been designed to assess a possible relation of vitamin $\mathrm{D}$ with the prognostic features in breast cancer or with regard to the recent different molecular subtypes [30-34].

Vitamin D deficiency is a common medical condition worldwide [35]. Previous studies conducted in 18 countries located at different latitudes have shown that this is a phenomenon that also occurs in sunny regions [36], even in Brazil [37]. Consistent with previous trials [12-14,22], which report 50-74\% vitamin D deficiency in newly diagnosed breast cancer patients, our study demonstrated that $66.2 \%$ of patients with breast cancer had a deficient level of vitamin $\mathrm{D}$. This fact may have more impact when analyzed by clinicopathological parameters in our study, considering that compared to the patients with normal level of vitamin $\mathrm{D}$, those with a deficient level of vitamin $\mathrm{D}$ at

Table 3

Multivariate-adjusted stratified analyses of clinicopathological variables according to serum of 25-hydroxy vitamin D levels.

\begin{tabular}{lllll}
\hline Variables & OR $($ CI 95\%) & $P$-value & OR $($ CI 95\%) & $P$-value \\
\hline ER negative & $3.77(1.76-8.09)$ & 0.0007 & $3.99(1.83-8.68)$ & 0.0005 \\
Ki-67 $\geq 14 \%$ & $2.50(1.35-4.63)$ & 0.003 & $2.62(1.40-4.98)$ & 0.003 \\
Lymph node positive & $1.59(1.03-2.33)$ & 0.048 & $1.58(1.02-2.92)$ & 0.042 \\
\hline
\end{tabular}

Note: Only statistically significant results are present. Other variables did not show significance.

OR, Odds Ratio; CI, confidence interval; ER, estrogen receptor.

Significantly different if $p<0.05$ (Logistic regression).

a $\mathrm{OR}$ (CI $95 \%$ ) for vitamin D values $<30 \mathrm{ng} / \mathrm{mL}$, adjusted for age, time since menopause and body mass index.

${ }^{\mathrm{b}}$ OR (CI 95\%) for vitamin D values $<20 \mathrm{ng} / \mathrm{mL}$, adjusted for age, time since menopause and body mass index. diagnosis had a greater risk of breast cancer with grade 3 disease, higher rate of positive lymph node status, locally advanced and metastatic disease and ultimately a worse prognosis. This is in accordance with literature data showing that locally advanced breast cancer patients have more severe vitamin D deficiency than those with early stage disease [30,34]. Thanasitthichai et al. [33] conducted a crosssectional analysis of vitamin D levels and clinicopathological features in 200 cases of breast cancer. Low vitamin D level $(<32 \mathrm{ng} / \mathrm{mL})$ was significantly found in the majority of cases with advanced stage disease, positive lymph node involvement and large tumors [33]. Hatse et al. [38] correlated serum 25(OH)D levels with tumor features and clinical disease outcome in 1800 early breast cancer patients. Lower 25(OH)D serum levels significantly correlated with larger tumor size at diagnosis but not with lymph node invasion, receptor status, or tumor grade. High serum 25(OH)D (>30 ng/mL) at diagnosis significantly correlated with improved overall survival and disease-specific survival. However, when considering menopausal status, serum 25(OH)D had a strong impact on breast cancer-specific outcome in postmenopausal patients, whereas no association could be demonstrated in premenopausal patients [38]. In view of the increasing number of cancer survivors and the high prevalence of vitamin D deficiency among patients with cancer, an evaluation of the role of circulating 25-OHD in prognosis among these patients is essential [39].

It suggests that lower serum vitamin $\mathrm{D}$ levels might have some contribution in the progression from early-stage to advanced disease as a result of altered gene transcription, supporting the hypothesis that vitamin $\mathrm{D}$ deficient has a role in the pathogenesis and progression of breast cancer [6]. Vitamin D appears to exert antiproliferative effect on breast cancer, mediated by the regulation of the expression of molecules that control the progression of the cell cycle [40]. Malignant cells have decreased intracellular levels of $1 \alpha$-hydroxylase (the activating enzyme encoded by CYP27B1) compared to normal cells, which increases intracellular vitamin D production [33]. Furthermore, some studies have demonstrated a reduction in vitamin receptor (VDR) expression in breast cancer cells compared to normal breast cells, by VDR gene polymorphisms $[41,42]$. During malignant transformation of the breast, tumor cells lose the ability to synthesize the active form of vitamin $\mathrm{D}$ and to respond to the effects of vitamin $\mathrm{D}$ mediated by VDR [41]. In breast cancer, the expression of VDR varies from $58 \%$ to $80 \%$, with reports of patients with VDR-positive tumors showing a higher disease-free survival rate [7].

In our study, a lesser proportion of ER and PR-positive tumors and a higher Ki-67 were observed in patients with deficient vitamin D levels and, interestingly, all patients with biologically aggressive triple-negative tumor phenotype were vitamin $\mathrm{D}$ deficient. In regard to prognostic biomarkers and their relation with vitamin D level, similar results have been observed [43,44]. Estrogen receptor (ER) and progesterone receptor (PR) have long been accepted as playing a central role in the pathobiology and treatment of breast cancer by predicting an indolent and slowly growing tumor with longer time to disease recurrence [45]. Robien et al. [43] showed a strong relation between postmenopausal women with low vitamin D intake and a higher risk of negative estrogen and progesterone receptor breast cancers [43]. Shirazi et al. [44] investigated the potential association between prediagnostic serum 25(OH)D levels and the risk of different subtypes of breast cancer. The study was based on The Malmo Diet and Cancer Study recruiting 17,035 women from 1991 to 1996 . A total of 764 incident breast cancers with matched controls were analyzed for $25(\mathrm{OH})$ $\mathrm{D}$ in samples collected at baseline, before diagnosis. As compared to the firsttertile of 25OHD3, the second tertile had a significantly lower risk of ER and PR-negative tumors and with a high expression of Ki-67. However, the third tertile had a similar risk as the first one [44].

The relationship of vitamin D with breast cancer risk may be subtype-specific, with emerging evidence of stronger effects of vitamin D in more aggressive breast cancers [46]. An aggressive subtype of breast cancer is the triple negative breast cancer, which lacks expression of ER 
and PR, does not have amplification of HER2 and expresses a high proliferation rate [5]. In our study, all cases of triple negative were detected in vitamin D deficient women. In the current literature, some studies have shown that while vitamin D deficiency is common in all breast cancer patient populations, it is particularly prevalent in those with these triple negative tumors [47]. Park et al. [48], in a large case-control study, compared serum 25(OH)D between breast cancer patients and general population. The adjusted odds ratio (OR) for breast cancer comparing women with deficient level of serum 25(OH)D to women with sufficient level of serum 25(OH)D was 1.27 (1.15-1.39). The association remained significant in both positive and negative hormone receptor (HR) status of the tumor. However, this association was more pronounced in HR-negative breast cancer, particularly with triple-negative breast cancer patients $(1.45,95 \%$ CI1.15-1.82) [48]. Since studies have demonstrated a high prevalence of vitamin D deficiency in women with basal-like breast cancer, correction of vitamin D deficiency in these women represents a reasonable, but yet untested, strategy to delay recurrence and extend survival [47].

As a strength of our study, the serum vitamin D was measured immediately after diagnosis of breast cancer and prior to any proposed treatment. In fact, some studies that have found an association between reduced values of $25(\mathrm{OH}) \mathrm{D}$ and a higher incidence of breast cancer performed the dosage of $25(\mathrm{OH}) \mathrm{D}$ during or after treatment, with a long interval from the diagnosis $[10,11]$, which could have potential modifications from the cancer treatment. For instance, women with a lower physical activity rate have lower values of $25(\mathrm{OH}) \mathrm{D}$, and it is well established that physical activity is consistently decreased for years following a breast cancer diagnosis [49]. Vrieling et al. [13], in a prospective cohort study, assessed the effect of post-diagnosis serum 25(OH)D on overall survival and distant disease-free survival in 1295 incident postmenopausal breast cancer patients (50-74 years), with a mean follow-up of 5.8 years. The association with overall survival was found to be significant only for 25(OH)D levels of blood samples collected before initiating chemotherapy, but not for those collected after chemotherapy had been administered [13]. A meta-analysis, which correlated serum 25(OH)D with breast cancer risk, confirmed an inverse correlation in case-control studies that collected25(OH)D immediately after breast cancer diagnosis, but not in prospective studies when $25(\mathrm{OH}) \mathrm{D}$ measurement was performed years before diagnosis [50].

Due to the nature of our data, our results do not allow for definite causal conclusions, i.e., whether low 25(OH)D levels cause worse prognostic features in breast cancer. As breast cancer is a disease that develops over several years, a major assumption for a causal relationship between 25OHD levels and breast cancer is that 25OHD levels, in the individual subject, are at a steady level for a longer period of time. Thus, a limitation of our study is that only a single measurement of vitamin D at diagnosis was used, which might not necessarily represent vitamin $\mathrm{D}$ levels at the time of cancer initiation. However, in a study, the correlation coefficient for measurement of 25(OH)D concentrations in serum samples collected in 1994 and 2008 ranged from 0.42 to 0.52 [30], suggesting a reasonable stability of endogenous vitamin D status. However, more studies are needed on whether a single measurement of serum 25OHD level is a sensitive indicator of an individual long-term vitamin D status.

In conclusion, in Brazilian postmenopausal women with breast cancer, there was an association between vitamin D insufficiency or deficiency and tumors with worse prognostic features. Low vitamin D levels were shown to be a risk factor for estrogen receptor-negative tumors, positive axillary lymph node status and a higher rate of cell proliferation.

\section{Funding}

This study was supported by the Sao Paulo Research Foundation (FAPESP) (grant number 2014/19382-3).

\section{Conflict of interest}

The authors have declared no conflict of interest. The authors have no commercial, proprietary, or financial interest in the products or instruments described in this article.

\section{References}

[1] American Cancer Society, Breast Cancer Facts \& Figs. 2015-2016, American Cancer Society Inc., Atlanta, 2015.

[2] Estimate 2017, Incidence of cancer in Brazil/National Cancer Institute José Alencar Gomes da Silva, INCA, Rio de Janeiro, 2016.

[3] M.T. Weigel, M. Dowsett, Current and emerging biomarkers in breast cancer: prognosis and prediction, Endocr. Relat. Cancer 17 (2010) R545-R262.

[4] A. Goldhirsch, W.C. Wood, A.S. Coates, R.D. Gelber, B. Thürlimann, H.J. Senn, Panel members, Strategies for subtypes-dealing with the diversity of breast cancer: highlights of the St. Gallen international expert consensus on the primary therapy of early breast cancer 2011, Ann. Oncol. 22 (2011) 1736-1747.

[5] A. Goldhirsch, E.P. Winer, A.S. Coates, R.D. Gelber, M. Piccart-Gebhart, B. Thürlimann, H.J. Senn, Panel members Personalizing the treatment of women with early breast cancer: highlights of the St Gallen international expert consensus on the primary therapy of early breast cancer, Ann. Oncol. 24 (2013) 2206-2223.

[6] M.F. Holick, Vitamin D: its role in cancer prevention and treatment, Prog. Biophys. Mol. Biol. 92 (2006) 49-59.

[7] D.K. Mishra, Y. Wu, M. Sarkissyan, S. Sarkissyan, Z. Chen, X. Shang, M. Ong, D. Heber, H.P. Koeffler, J.V. Vadgama, Vitamin D receptor gene polymorphisms and prognosis of breast cancer among African-American and Hispanic women, PLoS One 8 (2013) e57967.

[8] J. Welsh, J.A. Wietzke, G.M. Zinser, B. Byrne, K. Smith, C.J. Narvaez, Vitamin D-3 receptor as a target for breast cancer prevention, J. Nutr. 133 (2003) 2425S-2433S.

[9] C.J. Narvaez, D. Matthews, E. LaPorta, K.M. Simmons, S. Beaudin, J.O. Welsh, The impact of vitamin D in breast cancer: genomics pathways, metabolism, Front. Physiol. 5 (2014) 1-8.

[10] L.C. Lowe, M. Guy, J.L. Mansi, C. Peckitt, J. Bliss, R.G. Wilson, K.W. Colston, Plasma 25-hydroxyvitamin D concentrations: vitamin D receptor genotype and breast cancer risk in a UK Caucasian population, Eur. J. Cancer 41 (2005) 1164-1196.

[11] S. Abbas, J. Linseisen, T. Slanger, S. Kropp, E.J. Mutschelknauss, D. Flesch-Janys, J. Chang-Claude, Serum 25-hydroxyvitamin D and risk of post-menopausal breast cancer: results of a large case-control study, Carcinogenesis 29 (2008) 93-99.

[12] L. Rejnmark, A. Tietze, P. Vestergaard, L. Buhl, M. Lehbrink, L. Heickendorff, L. Mosekilde, Reduced prediagnostic 25-hydroxyvitamin D levels in women with breast cancer: a nested case-control study, Cancer Epidemiol. Biomarkers. Prev. 18 (2009) 2655-2660.

[13] A. Vrieling, R. Hein, S. Abbas, A. Schneeweiss, D. Flesch-Janys, J. Chang-Claude, Serum 25- hydroxyvitamin D and postmenopausal breast cancer survival: a prospective patient cohort study, Breast Cancer Res. 17 (2011) R74.

[14] P. Engel, G. Fagherazzi, A. Boutten, T. Dupré, S. Mesrine, M. Boutron-Ruault, F. Clavel-Chapelon, Serum 25(OH) vitamin D and risk of breast Cancer: a nested case-control study from the French E3N cohort, Cancer Epidemiol. Biomark. Prev. 19 (2011) 2341-2350.

[15] M.L. McCullough, V.L. Stevens, R. Patel, E.J. Jacobs, E.B. Bain, R.L. Horst, S.M. Gapstur, M.J. Thun, E.E. Calle, Serum 25-hydroxyvitamin D concentrations and postmenopausal breast cancer risk: a nested case control study in the cancer prevention study-II nutrition cohort, Breast Cancer Res. 11 (2009) R64.

[16] A.H. Eliassen, D. Spiegelman, B.W. Hollis, R.L. Horst, W.C. Willett, S.E. Hankinson, Plasma 25-hydroxyvitamin D and risk of breast cancer in the Nurses' Health Study II, Breast Cancer Res. 13 (2011) R50.

[17] T. Kuhn, R. Kaaks, S. Becker, P.P. Eomois, F. Clavel-Chapelon, M. Kvaskoff, L. Dossus, A. Tjønneland, A. Olsen, K. Overvad, J. Chang-Claude, A. Lukanova, B. Buijsse, H. Boeing, A. Trichopoulou, P. Lagiou, C. Bamia, G. Masala, V. Krogh, C. Sacerdote, R. Tumino, A. Mattiello, G. Buckland, M.J. Sánchez, V. Menéndez, M.D. Chirlaque, A. Barricarte, H.B. Bueno-de-Mesquita, F.J. van Duijnhoven, C.H. van Gils, M.F. Bakker, E. Weiderpass, G. Skeie, M. Brustad, A. Andersson, M. Sund, N. Wareham, K.T. Khaw, R.C. Travis, J.A. Schmidt, S. Rinaldi, I. Romieu, V. Gallo, N. Murphy, E. Riboli, J. Linseisen, Plasma 25-hydroxyvitamin D and the risk of breast cancer in the European prospective investigation into cancer and nutrition: a nested case-control study, Int. J. Cancer 133 (2013) 1689-1700.

[18] S. Scarmo, Y. Afanasyeva, P. Lenner, K.L. Koenig, R.L. Horst, T.V. Clendenen, A.A. Arslan, Y. Chen, G. Hallmans, E. Lundin, S. Rinaldi, P. Toniolo, R.E. Shore, A. Zeleniuch-Jacquotte, Circulating levels of 25-hydroxyvitamin D and risk of breast cancer: a nested case-control study, Breast Cancer Res. 15 (2013) R15.

[19] J. Wang, A.H. Eliassen, D. Spiegelman, W.C. Willett, S.E. Hankinson, Plasma free 25-hydroxyvitamin D, vitamin D binding protein, and risk of breast cancer in the Nurses' Health Study II, Cancer Causes Control. 25 (2014) 819-827.

[20] B. Dawson-Hughes, R.P. Heaney, M.F. Holick, P. Lips, P.J. Meunier, R. Vieth, Estimates of optimal vitamin D status, Osteoporos. Int. 16 (2005) 713-716.

[21] M.L. Neuhouser, B. Sorensen, B.W. Hollis, A. Ambs, C.M. Ulrich, A. McTiernan, L. Bernstein, S. Wayne, F. Gilliland, K. Baumgartner, R. Baumgartner, R. BallardBarbash, Vitamin D insufficiency in a multiethnic cohort of breast cancer survivors, Am. J. Clin. Nutr. 88 (2008) 133-139.

[22] P.J. Goodwin, M. Ennis, K.I. Pritchard, J. Koo, N. Hood, Prognostic effects of 25hydroxyvitamin d levels in early breast cancer, J. Clin. Oncol. 27 (2009) 3757-3763. 
[23] S.B. Mohr, E.D. Gorham, J. Kim, H. Hofflich, C.F. Garland, Meta-analysis of vitamin D sufficiency for improving survival of patients with breast cancer, Anticancer. Res. 34 (2014) 1163-1166.

[24] NCEP - Expert Panel on Detection E, Treatment of high blood cholesterol in A executive summary of the third report of the national cholesterol education program (NCEP) expert panel on detection, evaluation, and treatment of high blood cholesterol In adults (Adult treatment panel III), JAMA 285 (2001) 2486-2497.

[25] E.W. Elston, I.O. Ellis, Method for grading breast cancer, J. Clin. Pathol. 46 (1993) $189-190$.

[26] W.J. Gradishar, B.O. Anderson, R. Balassanian, S.L. Blair, H.J. Burstein, A. Cyr, A.D. Elias, W.B. Farrar, A. Forero, S.H. Giordano, M. Goetz, L.J. Goldstein, C.A. Hudis, S.J. Isakoff, P.K. Marcom, I.A. Mayer, B. McCormick, M. Moran, S.A. Patel, L.J. Pierce, E.C. Reed, K.E. Salerno, L.S. Schwartzberg, K.L. Smith, M.L. Smith, H. Soliman, G. Somlo, M. Telli, J.H. Ward, D.A. Shead, R. Kumar, Invasive Breast cancer version 1.2016: NCCN clinical practice guidelines in oncology, J. Natl. Compr. Cancer Netw. 13 (2015) 1475-1485.

[27] M.E. Hammond, D.F. Hayes, M. Dowsett, D.C. Allred, K.L. Hagerty, S. Badve, P.L. Fitzgibbons, G. Francis, N.S. Goldstein, M. Hayes, D.G. Hicks, S. Lester, R. Love, P.B. Mangu, L. McShane, K. Miller, C.K. Osborne, S. Paik, J. Perlmutter, A. Rhodes, H. Sasano, J.N. Schwartz, F.C. Sweep, S. Taube, E.E. Torlakovic, P. Valenstein, G. Viale, D. Visscher, T. Wheeler, R.B. Williams, J.L. Wittliff, A.C. Wolff, American society of clinical oncology/college of American pathologists guideline recommendations for immunohistochemical testing of estrogen and progesterone receptors in breast cancer, Arch. Pathol. Lab. Med. 134 (2010) 907-922.

[28] A.C. Wolff, M.E. Hammond, D.G. Hicks, M. Dowsett, L.M. McShane, K.H. Allison, D.C. Allred, J.M. Bartlett, M. Bilous, P. Fitzgibbons, W. Hanna, R.B. Jenkins, P.B. Mangu, S. Paik, E.A. Perez, M.F. Press, P.A. Spears, G.H. Vance, G. Viale, D.F. Hayes, American society of clinical oncology; college of American pathologists. Recommendations for human epidermal growth factor receptor 2 testing in breast cancer: American society of clinical oncology/college of American pathologists clinical practice guideline update, Arch. Pathol. Lab. Med. 138 (2014) 241-256.

[29] I.A. Kermani, H.T. Kojidi, J.V. Gharamaleki, Z. Sanaat, J.E. Ziaei, A. Esfahani, S. Seifi, M. Ghojazadeh, R. Dolatkhah, A.A. Kermani, Rad EG Association of serum level of 25 hydroxy-vitamin D with prognostic factors for breast cancer, Asian Pac. J. Cancer Prev. 12 (2011) 1381-1384.

[30] S. Yao, L.E. Sucheston, A.E. Millen, C.S. Johnson, D.L. Trump, M.K. Nesline, W. Davis, C.C. Hong, S.E. McCann, H. Hwang, S. Kulkarni, S.B. Edge, T.L. O'Connor, Ambrosone CB pretreatment serum concentrations of 25-hydroxyvitamin D and breast cancer prognostic characteristics: a case-control and a case-series study, PLoS One 6 (2011) e17251.

[31] L.J. Peppone, A.S. Rickles, M.C. Janelsins, M.R. Insalaco, K.A. Skinner, The association between breast cancer prognostic indicators and serum 25-OH vitamin D levels, Ann. Surg. Oncol. 19 (2012) 25909.

[32] J.G. Habib, J.L. Espirito, R.K. Harrell, B. Turnwald, J. O'Shaughnessy, E.H. Epstein, D.A. Patt, Vitamin D levels, triple-negative histology, and geography in breast cancer: a retrospective analysis of a large database of oncology practices in the United States, J. Clin. Oncol. 1 (2014) 32.

[33] S. Thanasitthichai, A. Chaiwerawattana, A. Prasitthipayong, Association of vitamin D level with clinicopathological features in breast cancer, Asian. Pac. J. Cancer. Prev. 16 (2015) 4881-4883.

[34] S. Yao, M.L. Kwan, I.J. Ergas, J.M. Roh, T.D. Cheng, C. Hong, S.E. McCann, L. Tang, W. Davis, S. Liu, C.P. Quesenberry, M.M. Lee, C.B. Ambrosone, L.H. Kushi, Association of serum level of vitamin D at diagnosis with breast cancer survival. A case-cohort analysis in the pathways study, JAMA Oncol. 3 (2017) 351-357.

[35] J. Hilger, A. Friedel, R. Herr, T. Rausch, F. Roos, D.A. Wahl, D.D. Pierroz, P. Weber, K. Hoffmann, A systematic review of vitamin D status in populations worldwide, $\mathrm{Br}$. J. Nutr. 114 (2014) 23-45.

[36] P. Lips, K. Hosking, K. Lipunner, J.M. Norquist, L. Wehren, G. Maalouf, S. Ragi-Eis J. Chandler, The prevalence of vitamin D inadequacy amongst women 25OHD with osteoporosis: an international epidemiological investigation, J. Intern. Med. 260 (2006) 245-254.

[37] M.D. Unger, L. Cuppari, S.M. Titan, M.C. Magalhaes, A.L. Sassaki, L.M. dos Reis, V. Jorgetti, R.M. Moyses, Vitamin D status in a sunny country: where has the sun gone? Clin. Nutr. 29 (2010) 784-788.

[38] S. Hatse, D. Lambrechts, A. Verstuyf, A. Smeets, B. Brouwers, T. Vandorpe, O. Brouckaert, G. Peuteman, A. Laenen, L. Verlinden, C. Kriebitzsch, A.S. Dieudonné, R. Paridaens, P. Neven, M.R. Christiaens, R. Bouillon, H. Wildiers, Vitamin D status at breast cancer diagnosis: correlation with tumor characteristics disease outcome, and genetic determinants of vitamin D insufficiency, Carcinogenesis 33 (2012) 1319-1326.

[39] A.T. Toriola, N. Nguyen, K. Scheitler-Ring, G.A. Colditz, Circulating 25-hydroxyvitamin d levels and prognosis among cancer patients: a systematic review, Cancer Epidemiol. Biomark. Prev. 23 (2014) 917-933.

[40] N. Lopes, B. Sousa, D. Martins, M. Gomes, Vieira, Alterations in vitamin D signaling and metabolic pathways in breast cancer progression: a study of VDR, CYP27B1 and CYP24A1 expression in benign and malignant breast lesions, BMC Cancer 10 (2012) 483.

[41] J.L. Costa, P.P. Eijk, M.A. van de Wiel, D. Berge, F. Schmitt, C.J. Narvaez, J. Welsh, B. Ylstra, Anti-proliferative action of vitamin D in MCF7 is still active after siRNAVDR knock-down, BMC Genomics 10 (2009) 499.

[42] L.S. Engel, I. Orlow, C.S. Sima, J. Satagopan, U. Mujumdar, P. Roy, S. Yoo, D.P. Sandler, M.C. Alavanja, Vitamin D receptor gene haplotypes and polymorphisms and risk of breast cancer: a nested case-control study, Cancer Epidemiol. Biomark. Prev. 21 (2012) 1856-1867.

[43] K. Robien, G.J. Cutler, D. Lazovich, Vitamin D intake and breast cancer risk in postmenopausal women: the Iowa Women's Health Study, Cancer Causes Control. 18 (2007) 775-782.

[44] L. Shirazi, M. Almquist, S. Borgquist, J. Malm, J. Manjer, Serum vitamin D (25OHD3) levels and the risk of different subtypes of breast cancer: a nested caseecontrol study, Breast 28 (2016) 184-190.

[45] W.F. Anderson, N. Chatterjee, W.B. Ershler, O.W. Brawley, Estrogen receptor breast cancer phenotypes in the surveillance epidemiology, and end results database, Breast Cancer Res. Treat. 76 (2002) 27-36.

[46] S. Yao, C.B. Ambrosone, Associations between vitamin D deficiency and risk of aggressive breast cancer in African-American women, J. Steroid Biochem. Mol. Biol. 136 (2013) 337e41.

[47] E. LaPorta, J.E. Welsh, Modeling vitamin D actions in triple negative/basal-like breast cancer, J. Steroid Biochem. Mol. Biol. 144 (2014) 65-73.

[48] S. Park, D.H. Lee, J.Y. Jeon, J. Ryu, S. Kim, J.Y. Kim, H.S. Park, S.I. Kim, B.W. Park, Serum 25-hydroxyvitamin D deficiency and increased risk of breast cancer among Korean women: a case-control study, Breast Cancer Res. Treat. 152 (2015) $147-154$

[49] R.T. Chlebowski, Vitamin D and breast cancer: interpreting current Evidence, Breast Cancer Res. 13 (2011) 217.

[50] L. Yin, N. Grandi, E. Raum, U. Haug, V. Arndt, H. Brenner, Meta-analysis: serum vitamin D and breast cancer risk, Eur. J. Cancer 46 (2010) 2196-2205. 